\title{
Implementation of PC Controlled Wireless Video Transmitting Vehicle
}

\author{
Ramanathan P* \\ Department of Electrical and Electronics Engineering, Bharath University, \\ Chennai, Tamilnadu, India \\ *Corresponding author, e-mail: parmesh.ramanathan@wisc.edu
}

\begin{abstract}
Remote PC controlled video transmitting Surveillance Car is a microcontroller based configuration which send serial information from PC by means of chip to the auto. This auto works as indicated by the guideline given from PC. Remote transmission is behavior through transmitter to send the information and direction to the auto so it will work as indicated by the guideline given. It transmits continuous video back to PC to screen the whereabouts of the auto and to see the items and the obstructions in the way. It additionally peruses an entire picture from camera and sends it to the PC with the objective that we can surveillance through video transmission.
\end{abstract}

Keywords: personal computer, serial data

Copyright $@ 2017$ APTIKOM - All rights reserved.

\section{Introduction}

PC Controlled Wireless Video Transmitting Vehicle has a general purpose of broadcasting the image that could be seen on the computer monitor. This have a wireless camera built on it for transmitting the images to the computer. The advancement in the field of wireless communication and image processing has fascinated us in doing this project. The overall system consists of different sections assembled together to build the robot. This project uses a wireless vehicle to communicate with the computer via serial port of the computer and MATLAB programming language is used to link with the car [1-4]. The wireless camera, IP Robocam21, is an image and video transmitter which transmits image and video to the remote computer using the Radio AV receiver attached to the remote computer. The wireless link used for the motion of the robot is triggered through the serial port of the computer which transmits the control signal using the radio frequency. Frequency modulation works as the radio link which serves as the remote controller for the robot. Radio link makes the system wireless and hence enhancing the system for the control configuration [5-9].

In this project we will be designing the suitable and demonstrable mechanical part of car, electric circuits in order to drive the motors to run the car suitably and as per desired. And the signals for the electric circuits will be fetched from the programming part via wireless device. So, this project mainly comprises of following parts: mechanical, electrical, and programming part. The main objectives of this project are:

1. To perform a microcontroller based design.

2. Communicate the AVR ATmega16 with computer.

3. To conduct wireless transmission.

4. Design a PC controlled car.

5. To make video transmission and Surveillance through video transmission.

The term reconnaissance is regularly utilized for all types of perception or checking, not simply visual perception. Observation is the checking of the conduct, exercises, or other evolving data, more often than not of individuals with the end goal of affecting, overseeing, coordinating, or securing. The word reconnaissance is regularly used to depict perception from a separation by method for gear, (for example, CCTV cameras), or capture of electronically transmitted information (such as Internet movement or telephone calls) as shown in Figure 1. Notwithstanding, reconnaissance can likewise allude to straightforward, moderately no-or low-innovation systems, for example, human insight specialists and postal capture attempt [10-14].

Reconnaissance is exceptionally helpful to governments and law requirement to keep up social 
control, perceive and screen dangers furthermore in the logical exploration and innovation. The term reconnaissance is regularly utilized for all types of perception or checking, not simply visual perception. Observation is the checking of the conduct, exercises, or other evolving data, more often than not of individuals with the end goal of affecting, overseeing, coordinating, or securing. The word reconnaissance is regularly used to depict perception from a separation by method for gear, (for example, CCTV cameras), or capture of electronically transmitted information (such as Internet movement or telephone calls) as shown in Figure 2. Notwithstanding, reconnaissance can likewise allude to straightforward, moderately no-or low-innovation systems, for example, human insight specialists and postal capture attempt [15-18].

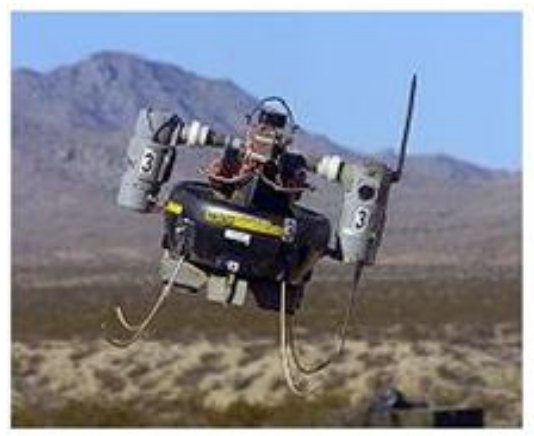

Figure 1. Aerial Surveillance

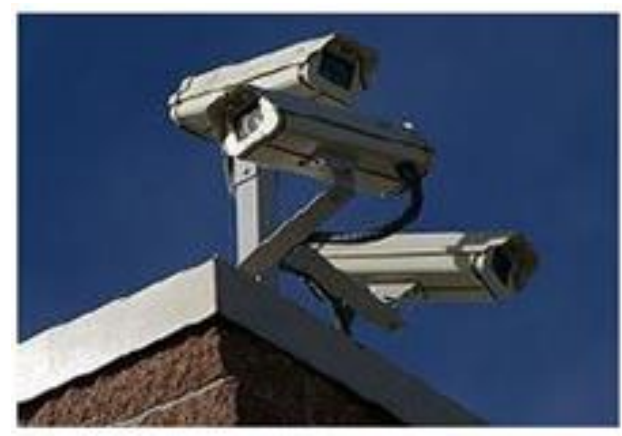

Figure 2. Surveillance System

\section{System Analysis:}

\subsection{Vehicle Control Section}

The Wireless surveillance car is a system which consists of following sub systems: Electrical, Mechanical and Computer systems are embedded together to work as a surveillance car that gives us the clear images of the object we want. The wireless signal is transmitted from the pc on the hand of operator and used to move the car accordingly. The keys of the pc are used for controlling the inputs to the car and that input generate corresponding code known to computer program $(\mathrm{C}, \mathrm{C}++)$. We are using GUI (graphics user interface) for it so that these codes are processed and using suitable program a corresponding digital signal is generated. The program we are using for it is Matlab program. Generated digital signal is fed to microcontroller which is in serial data format as microcontroller has serial input; here microprocessor acts as a interfacing unit. To match the speed between microcontroller and the computer we are using RS232A component. A MATLAB program using GUIDE is written, it acts as interface between human and machine. Instructions are written in MATLAB and send to the microcontroller via serial communication and RS232 standards. MATLAB GUI program for the interface has been written, program for the serial communication has also been written in mikroC. The data or instruction will send to the vehicle wirelessly using the RF module, and the data then will be send to the microcontroller for necessary execution and command for the vehicle. H-bridge will be used for the necessary turning of the vehicle as shown in Figure 3.

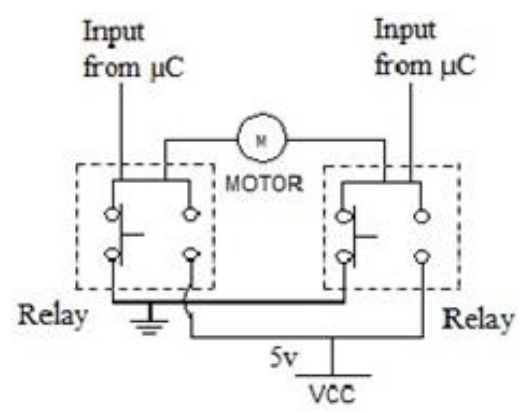

Figure 3. Construction of H-Bridge using relay 


\section{Serial Communication}

\subsection{DCE and DTE Devices}

DTE stands for Data Terminal Equipment, and DCE stands for Data Communications Equipment. These terms are utilized to show the pin-out for the connectors on a gadget and the bearing of the signs on the pins. Your PC is a DTE gadget, while most different gadgets, for example, modem and other serial gadgets are generally DCE devices.RS-232 has been around as a standard for a considerable length of time as an electrical interface between Data Terminal Equipment (DTE) and Data CircuitTerminating Equipment (DCE, for example, modems or DSUs.

\subsection{Synchronous data transfer}

In project to-program correspondence, synchronous correspondence requires that every end of a trade of correspondence react thusly without starting another correspondence. An average action that may utilize a synchronous convention would be a transmission of documents starting with one point then onto the next. As every transmission is gotten, a reaction is returned showing achievement or the need to resend.

\subsection{Asynchronous data transfer}

The term offbeat is typically used to depict correspondences in which information can be transmitted discontinuously as opposed to in a constant flow. For instance, a phone discussion is offbeat in light of the fact that both sides can talk at whatever point they like. On the off chance that the correspondence were synchronous, every gathering would be required to hold up a predetermined interim before talking. The trouble with offbeat interchanges is that the collector must have an approach to recognize legitimate information and commotion. In PC interchanges, this is generally refined through an uncommon begin bit and stop bit toward the starting and end of every bit of information as shown in Figure 4. Thus, offbeat correspondence is now and again called begin stop transmission.

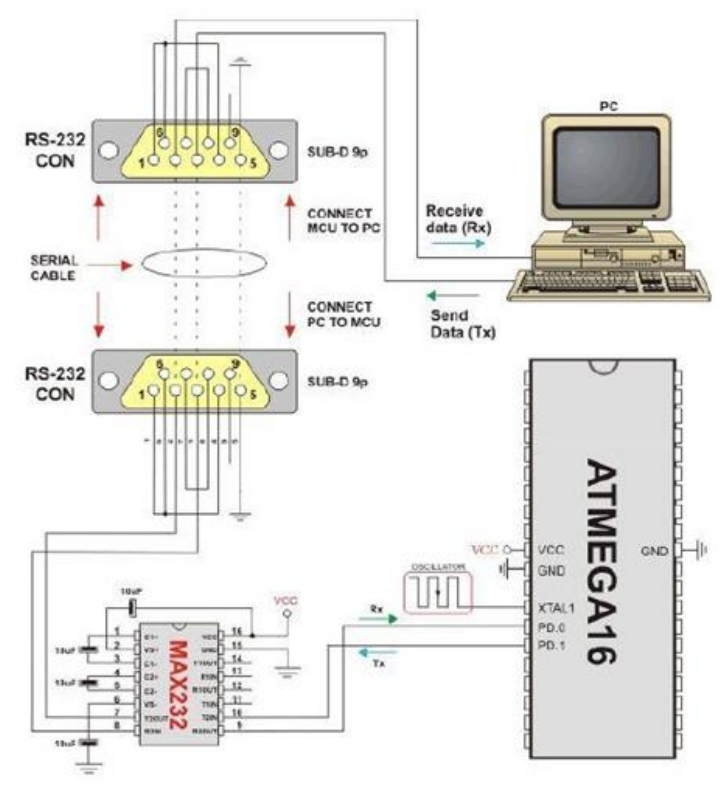

Figure 4. Serial Communication with Asynchronous UART connection

\subsection{RF and Wireless Transmission}

$\mathrm{RF}$ is the remote transmission of information by computerized radio signs at a specific recurrence as shown in Figure 5. It keeps up a two-way, online radio association between a versatile terminal and the host PC. The versatile terminal, which can be compact, even worn by the specialist, or mounted on a forklift truck, gathers and shows information at the purpose of movement. The host PC can be a PC, a minicomputer or a much bigger centralized computer. The benefits of a RF correspondence framework are numerous. Begin with the basic truth that on the off chance that it is remote, it don't need 
to lay link. Link is costly, less adaptable than RF scope and is inclined to harm. For new offices, actualizing a remote framework may be savvier than running link through modern situations, particularly if the space arrangement might change to backing distinctive storage room designation or adaptable assembling stations. A radio framework transmits data to the transmitter. The data is transmitted through a receiving wire which changes over the RF signal into an electromagnetic wave. The transmission medium for electromagnetic wave proliferation is free space. The electromagnetic wave is caught by the getting receiving wire which changes over it back to a RF signal. In a perfect world, this RF sign is the same as that initially produced by the transmitter. The first data is then demodulated back to its unique structure. Other general favorable circumstances of ongoing RF correspondence incorporate a critical change all together exactness $(>99 \%)$, the disposal of printed material, substitution of tedious group preparing by quick constant information handling, brief reaction times and enhanced administration levels. Supplementing an ongoing information gathering framework with robotized information passage by standardized tag filtering or another programmed information accumulation innovation enhances the exactness of data and wipes out the requirement for repetitive information section, which gives another arrangement of time-and cost-sparing focal points.

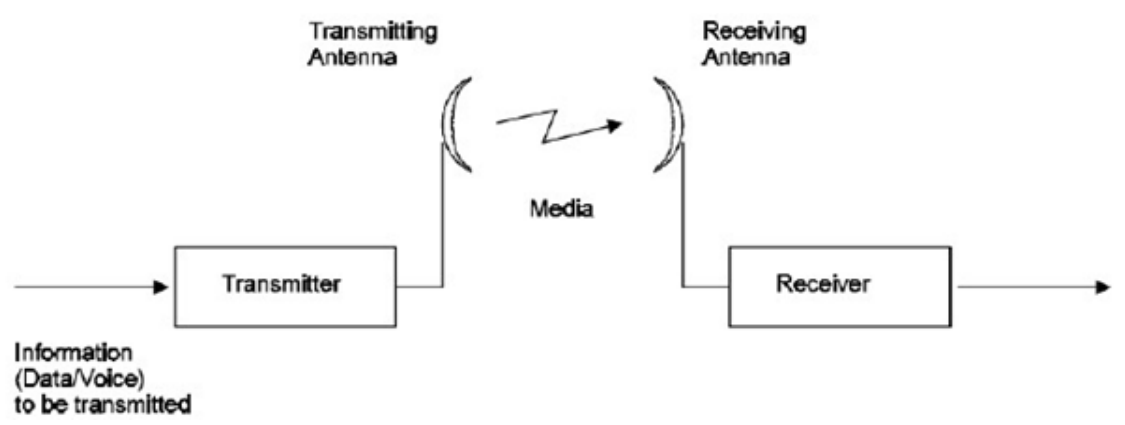

Figure 5. A typical radio system

The item will have higher devotion and will be flexible. Diverse fields can utilize the item for the different applications. From topographical investigation to the security framework this item will have the ability to satisfy the required reason. When all is said in done, the utilization and application can be summarized as:

1. Home security system.

2. Use in the military fields for the information collection.

3. Geographical exploration.

4. Path tracker and exploration beyond human reach

\section{Conclusion}

The final product of the project will be done on a PCB board and will be demonstrated with fully functioning mechanical part. The final product is supposed to represent the design concept of our product. The same concept can be utilized to construct other surveillance cars as a mass production for detection as well as scientific research purposes. However, the idea always has a lot of rooms to make enhancements in the future and the defects can be corrected to make the idea to be utilized in real practice. We anticipate a successful completion.

\section{References}

[1] Paper titled"Design Of PC Based Wireless Video Camera Positioning System For Wide Area Monitoring" by Banjar Brahma, Janarsing Narzary, Dilip Wary, International Journal of Engineering Research \& Technology, Vol.2 - Issue 6 (June - 2013).

[2] Jayalakshmi, V., Gunasekar, N.O., Implementation of discrete PWM control scheme on Dynamic Voltage Restorer for the mitigation of voltage sag /swell, 2013 International Conference on Energy Efficient Technologies for Sustainability, ICEETS 2013, pp-1036-1040, 2013.

APTIKOM J. CSIT Vol. 2, No. 2, 2017 : first_page - end_page 
[3] Kaliyamurthie, K.P., Parameswari, D., Udayakumar, R., QOS aware privacy preserving location monitoring in wireless sensor network, Indian Journal of Science and Technology, v-6, i-5, pp-4648-4652, 2013.

[4] Sundararajan, M., Optical instrument for correlative analysis of human ECG and breathing signal, International Journal of Biomedical Engineering and Technology, v-6, i-4, pp-350-362, 2011.

[5] Y. Anzai, S. Nishikata, and F. Tatsuta, "Studies on a sensorless initial rotor position estimating method for hybrid stepping motors," in Proc. Int. Conf. Elect. Mach. Syst., Nov. 2009, pp. 1-4.

[6] Khanaa, V., Thooyamani, K.P., Using triangular shaped stepped impedance resonators design of compact microstrip quad-band, Middle - East Journal of Scientific Research, v-18, i-12, pp-1842-1844, 2013.

[7] Thamotharan, C., Prabhakar, S., Vanangamudi, S., Anbazhagan, R., Anti-lock braking system in two wheelers, Middle - East Journal of Scientific Research, v-20, i-12, pp-2274-2278, 2014.

[8] Vanangamudi, S., Prabhakar, S., Thamotharan, C., Anbazhagan, R., Design and fabrication of dual clutch, Middle - East Journal of Scientific Research, v-20, i-12, pp-1816-1818, 2014.

[9] M. Boussak, "Implementation and experimental investigation of sensorless speed control with initial rotor position estimation for interior permanent magnet synchronous motor drive," IEEE Trans. Power Electron., vol. 20, no. 6, pp. 1413-1421, Nov. 2005.

[10] Sengottuvel, P., Satishkumar, S., Dinakaran, D., Optimization of multiple characteristics of EDM parameters based on desirability approach and fuzzy modeling, Procedia Engineering, v-64, i-, pp-1069-1078, 2013.

[11] Kaliyamurthie, K.P., Udayakumar, R., Parameswari, D., Mugunthan, S.N., Highly secured online voting system over network, Indian Journal of Science and Technology, v-6, i-SUPPL.6, pp-4831-4836, 2013.

[12] Khanaa, V., Thooyamani, K.P., Saravanan, T., Simulation of an all optical full adder using optical switch, Indian Journal of Science and Technology, v-6, i-SUPPL.6, pp-4733-4736, 2013.

[13] Raj, M.S., Saravanan, T., Srinivasan, V., A modified direct torque control of induction motor using space vector modulation technique, Middle - East Journal of Scientific Research, v-20, i-11, pp-1572-1574, 2014.

[14] Kumaravel, A., Dutta, P., Application of Pca for context selection for collaborative filtering, Middle - East Journal of Scientific Research, v-20, i-1, pp-88-93, 2014.

[15] Brintha Rajakumari, S., Nalini, C., An efficient data mining dataset preparation using aggregation in relational database, Indian Journal of Science and Technology, v-7, i-, pp-44-46, 2014.

[16] Udayakumar, R., Khanaa, V., Saravanan, T., Saritha, G., Retinal image analysis using curvelet transform and multistructure elements morphology by reconstruction, Middle - East Journal of Scientific Research, v-16, i-12, pp-1781-1785, 2013.

[17] Vanangamudi, S., Prabhakar, S., Thamotharan, C., Anbazhagan, R., Design and calculation with fabrication of an aero hydraulwicclutch, Middle - East Journal of Scientific Research, v-20, i-12, pp-1796-1798, 2014.

[18] Saravanan, T., Raj, M.S., Gopalakrishnan, K., VLSI based 1-D ICT processor for image coding, Middle - East Journal of Scientific Research, v-20, i-11, pp-1511-1516, 2014. 